\title{
Aprenentatge Basat en Projectes en àmbits STEM. Claus metodològiques i reptes
}

Jordi Domènech-Casal (jdomen44@xtec.cat) Institut Marta Estrada (Granollers). Grup LIEC, Departament de Didàctica de les Matemàtiques i les Ciències Experimentals, Universitat Autònoma de Barcelona

El desenvolupament competencial de les àrees científiques ha trobat en l'Aprenentatge Basat en Projectes un espai didàctic candidat. El treball coordinat des de les diverses disciplines (Ciències, Tecnologia, Enginyeria i Matemàtiques) permet aprendre tot instrumentalitzant els aprenentatges cap a un objectiu amb un sentit en el món real. El desplegament de la proposta ABP és una oportunitat, però és complex i s'enfronta a concepcions errònies sobre la metodologia i dificultats pràctiques en l'aplicació. Hem organitzat unes jornades per ajudar el professorat de secundària en el desenvolupament de propostes $A B P$ d'àmbit STEM, \#stemabp. En aquest article presentem el recull de materials que $n$ 'han resultat i proposem alguns eixos metodològics a considerar en l'ABP-STEM.

Paraules clau: ABP, CTEM, Currículum, Competències.

The development of the scientific competence has in Project-Based Learning a candidate didactic space. The coordinated work form several disciplines (Science, Technology, Engineering and Mathematics) allow to learn by doing in purposeful, meaningful projects. The deploy of PBL is an opportunity, and confronts misconceptions about the methodology and practical difficulties in its application. To help secondary education teachers to develop PBL activities in STEM areas, we have organized and carried a teacher-training event, \#stemabp. In this article, we present a collection of the resulting materials and propose some methodologic axes to be taken into account when developping PBL-STEM Science Education.

Keywords: PBL, STEM, Syllabus, Competences.

\section{L'ABP I L'ENSENYAMENT STEM}

Des que Kilpatrick (1918) va publicar el seu opuscle "The Project Method", l'Aprenentatge Basat per Projectes ha estat cercant formes de materialitzar-se com a metodologia didàctica (Sanmartí, 2016). En la seva proposta original, Kilpatrick definí 4 tipus de projectes, segons el propòsit que els animava, i que podríem resumir en: elaborar un producte, resoldre un problema, gaudir d'una experiència estètica o aprendre una habilitat concreta. Avui, les reformulacions actuals (Larmer, Mergendoller i Boss, 2015) semblen centrar-se en els tres primers tipus, que comparteixen la presència d'un objectiu extern a l'aprenentatge que actua com a promotor de l'aprenentatge, amb la idea que l'apre- nentatge es produeix quan el currículum s'instrumentalitza en contextos reals o versemblants, com proposen alguns autors (Gilbert, 2006, Sanmartí, Burgoa i Nuño 2011). Sota aquesta definició genèrica d'ABP, en realitat, podem acollir-hi metodologies molt diverses (Sanmartí, 2016, DomènechCasal, en avaluació) i en molts casos anteriors a aquesta definició, des de l'Aprenentatge-Servei (Martín, 2016), les WebQuest (Fierro, 2005), les Controvèrsies Sòcio-Científiques (Sadler, 2009), l'Educació pel Desenvolupament, la Indagació (Caamaño, 2011), la Ciència Ciutadana (Bonney et al., 2009), o el Creative Thinking, però en tot cas, solen afegir dos elements metodològics a la forma genèrica de l'objectiu extern: implica en certa manera un conflicte o repte a resoldre, i els aprenents tenen 
un paper actiu que exerceixen en comunitat (Domènech-Casal, 2016).

Aquesta reformulació ha resultat ben acollida, especialment en una Secundària que brega des de fa temps en trobar un espai metodològic prou ric i reconeixible des de les diferents àrees científiques per a materialitzar el treball per competències (Grau, 2009, Chiva i Martí, 2016), de manera que fins i tot a la premsa convencional es parla de l'ABP (Rodríguez, 2015). D'aquest interès i també (perquè negar-ho) de les necessitats econòmiques d'un món occidental que se sap depenent d'un teixit científic i tecnològic potent i una societat científicament alfabetitzada, emergeix la proposta STEM (Science, Technology, Engineering and Mathematics), una visió particular de l'Aprenentatge Basat en Projectes orientada als àmbits científics (Bybee, 2010), que comparteix els eixos de l'ABP (objectiu extern, repte i comunitat) i s'interessa a enllaçar de forma clara el currículum de les àrees científiques amb el món real.

\section{PER QUĖ UNES JORNADES STEM-ABP}

El desenvolupament d'aquesta línia didàctica i el seu vincle com a metodologia per a desenvolupar el currículum s'ha vist en ocasions obstruït per algunes visions sobre l'ABP:

1) El discurs que tot $A B P$ ha de ser -forçosamentcurricularment interdisciplinari, i organitzativament mastodòntic.

2) La concepció que en l'ABP és necessari que siguin els alumnes els qui escullin l'objectiu del projecte (o, fins i tot, els d'aprenentatge);

3) El discurs que afirma que continguts i competències són excloents, o que els projectes no serveixen per a aprendre continguts, sinó exclusivament altres "habilitats" de caire genèric, com cercar informació, treballar en equip, o comunicar en públic.

Aquestes visions són poc representatives del panorama divers i les possibilitats pedagògiques de I'ABP i hem cregut necessari oferir un espai de difusió de pràctiques \#STEM \#ABP orientat a mostrar que:

1) L'ABP pot ser desenvolupat des d'una matèria o més d'una, en funció del paper que hi jugui el context;

2) Més enllà d'una filosofia de l'aprenentatge, on es transforma l'aprenentatge en un projecte individual de l'alumne, l'ABP pot ésser també una metodologia didàctica, on es materialitza el currículum de manera clara;
3) L'ABP no és un currículum alternatiu que "sacrifica" continguts, sinó una metodologia win-win que reforça el vincle entre continguts i competències

Amb l'objectiu d'ampliar la visió sobre l'ABP i oferir orientació en aspectes tècnics i metodològics del seu desenvolupament, en col•laboració amb el CESIRE i la Fundació Catalana per la Recerca i la Innovació, hem dut a terme la primavera de 2017 les Jornades \#STEMABP [1]. Les jornades s'han desenvolupat al llarg de quatre sessions i han convocat ponents experts de les diverses àrees STEM (Ciències, Matemàtiques, Tecnologia) al voltant d'una proposta formativa que s'ha estructurat de la manera següent:

- La connexió i progressió del currículum de les àrees amb el context: les dues primeres sessions s'han fet 8 ponències de projectes d'àrea de cadascuna de les àrees (Ciències, Tecnologia i Matemàtiques), la segona sessió 4 ponències de projectes interdisciplinaris elaborats des d'àmbits STEM i la tercera sessió una taula rodona connectant l'ABP com a metodologia també en espais fora dels centres educatius.

- Una visió pràctica, coherent amb el propi discurs de l'ABP, d'aprendre instrumentalitzant: a cadascuna de les sessions, els participants han elaborat i comunicat una proposta.

- La voluntat de connectar pràctica i discurs i participar en la creació de coneixement pedagògic al voltant de l'ABP: El contingut de les ponències i les reflexions metodològiques ha estat enviat per a la seva publicació en revistes de didàctica específica.

\section{UN ESPAI METODOLÒGICAMENT DI- VERS ON LES ÀREES STEM TENEN MOLT A DIR}

El conjunt de les aportacions a les jornades han mostrat la vitalitat i potencial d'aquesta metodologia en les àrees STEM.

Des de l'àrea de Ciències Experimentals (Física, Química, Biologia i Geologia) 8 ponències (Marchán-Carvajal et al., 2017, Touron et al., 2017) s'han encarregat de mostrar que els contextos quotidians, els escenaris reals o versemblants que impliquen conflictes científics, els gèneres de comunicació científica i el rol investigador de l'alumne situen les Ciències en un espai d'aprenentatge (models científics, habilitats científiques, visions epistèmiques) més ric, complet i propi de l'àrea. 
Des de l'àrea de Tecnologia vuit ponències (Villar, Zurita i Giménez, 2017, Josa et al., 2017), mostren que referents habituals de la tecnologia (l'electricitat, la fusta, els automatismes i la programació, el procés tecnològic) poden ser reinterpretats des d'una visió pedagògica del context que implica canvis, també, en aspectes avaluatius.

Des de l'àrea de Matemàtiques, 8 ponències (Planella et al., 2017, Margelí et al., 2017) posen en evidència que l'espai, la forma, la creativitat, les conjectures, i la planificació ubiquen les matemàtiques en un context didàctic que trenca les barreres que les limitaven a una matèria instrumental, donant veu al seu discurs.

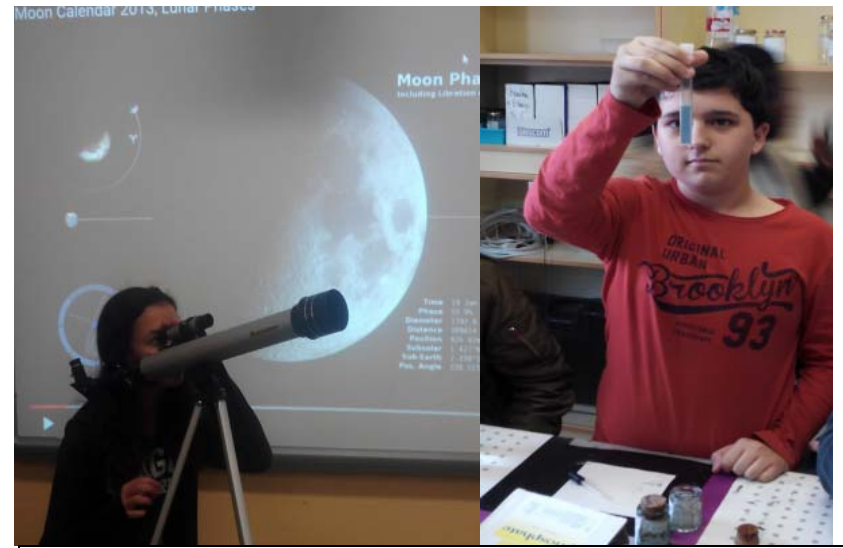

Figura 1. L'ABP és un espai candidat per al desplegament de la proposta STEM. Imatges d'alumnes en diferents activitats STEM a l'Institut Marta Estrada, de Granollers.

La connexió amb l'entorn, l'orientació al servei i les vies organitzatives per aconseguir que les diferents matèries donin resposta a les necessitats que el context demanda s'exemplifiquen en els cinc projectes que es discuteixen en les ponències interdisciplinàries (Redondo et al., 2017) i que han evidenciat la oportunitat que suposa la interdisciplinarietat en l'àmbit STEM.

La Taula Rodona ha tingut per objectiu conèixer com aprenen els adolescents quan aprenen per projectes fora dels centres educatius. Des de l'escoltisme, els esbarts dansaires i les orquestres juvenils ens han aportat visions inspiradores sobre avaluació, ritmes d'aprenentatge, autonomia, que trenquen algunes convencions arbitràries del sistema educatiu.

\section{CLAUS METODOLÒGIQUES I REPTES STEM ABP}

De les discussions i experiències durant les jornades $i$ en altres espais vinculats a l'ABP la formació STEM, n'hem extret claus i reptes, que enumerem a continuació:

STEM ABP és un escenari cap a la Competència Científica i Tecnològica, ja que la competència implica la capacitat de transferir els coneixements a situacions noves i imprevistes, ubicades en context, element clau de l'ABP. Això implica identificar contexts reals $\mathrm{i}$ gèneres comunicatius propis de les àrees per a usar-los en la creació d'activitats, el que implica una certa investigació dels escenaris del món científic de fora de l'aula per part de l'alumnat, però també per part dels docents, tal com proposen iniciatives com la formació CTM [2]. Així mateix, una mirada "des de la competència científica" i les seves dimensions (conceptual, procedimental i epistèmica) pot ajudar a redefinir o a fer més competencials les propostes ABP (Domènech-Casal, 2017). Cal tenir en compte també que l'adquisició de la competència científica i tecnològica no hauria de prioritzar formar més i millors treballadors d'àmbits STEM, sinó formar ciutadans més competents per a exercir la seva ciutadania en àmbits participats per la ciència, la tecnologia i les matemàtiques.

Els discursos i referents propis de les àrees STEM són punts clau per ajudar als docents a connectar amb la metodologia ABP com a espai dignificador del coneixement de les àrees i el seu discurs. Per això, és important proposar vies assumibles per al canvi des d'allò que ja s'està fent bé o allò que els docents de l'àrea ja identifiquen com a espais de qualitat pedagògica en el discurs de l'àrea (indagació, WebQuests, Ciència Ciutadana, pràctiques de laboratori, procés constructiu, modelització, matemàtiques manipulatives, conjectures...) (Domènech-Casal, 2016). Els discursos orientats a "la desaparició de les assignatures" (Rodríguez, 2015) són poc útils (ja que generen poca complicitat) i irreals: precisament, cada àrea té una mirada que cal que els alumnes desenvolupin, i interpel•lar els contexts des de diferents àrees és el que permet que el context sigui útil per a generar nous coneixements. La interdisciplinarietat (inclòs entre les matèries STEM) hauria de ser una demanda del context, i no un a priori de l'ABP.

La convivència dels objectius del projecte (p.ex:construir un vaixell) i els objectius d'aprenentatge (p.ex: treball amb fusta, flotació, dibuix tècnic,...) és una complexitat pròpia de l'ABP que cal tenir en compte. Cal fer molta atenció a quins 
són els objectius d'aprenentatge, quin és el paper dels continguts i saber què pretenem que aprenguin en cada projecte i en quin punt del projecte ho aprenen (Miró et al., 2016). Incloure en el projecte objectius d'aprenentatge que en realitat no fan falta per a l'assoliment de l'objectiu del projecte és una pràctica que no és coherent amb la metodologia. De la mateixa manera, cal fer atenció a quins aprenentatges temàticament propers no s'estan realment aprenent en el projecte, i com es resol això.

És natural que els projectes no segueixin el Cicle d'aprenentatge paradigmàtic (exploracióintroducció de coneixements-estructuració-aplicació i transferència) (Jorba i Caselles, 1996), sinó que aquestes etapes quedin colılapsades en prioritzar com a eix narratiu de l'acció el desenvolupament de l'objectiu del projecte (Domènech-Casal, en avaluació). Tot i això, cal assegurar-se d'incloure en els projectes etapes d'estructuració de coneixements. Cal fer especial atenció a com es comunica a l'alumnat (i a les famílies), l'existència dels dos tipus d'objectius i com es treballen i s'assoleixen (En aquest projecte hem volgut aconseguir....per a ferho, hem après/a...).

La reflexió sobre l'avaluació i els reptes particulars que implica l'ABP han de ser tinguts en compte. Cal, però, fer una diferència: una cosa són els reptes generals que la innovació pedagògica proposa respecte a l'avaluació independentment de la metodologia d'aprenentatge (avaluació formadora i formativa,...) i les eines que proposa (coavaluació, portfolios, rúbriques, etc.) i una altra els reptes sobre avaluació que pertanyen específicament a l'ABP. Entre aquests, cal considerar concretament: 1) la complexitat de tenir una visió individualitzada de l'aprenentatge sobre la base de productes col-lectius; 2) la complexitat de distingir entre criteris d'avaluació dels productes (vinculats a l'objectiu del projecte) i criteris d'avaluació dels aprenentatges (vinculats als objectius d'aprenentatge). Les ponències de les jornades han aportat dues eines que es dirigeixen específicament a aquestes preguntes: CoRubrics [3] i AssessABP [4].

La necessitat de definir tipus d'ABP i les seves possibilitats pedagògiques, diferenciant què es pretén i es pot aconseguir amb cadascun, és un aspecte relacionat amb els dos punts anteriors: el paper dels models científics, els contexts, el grau d'obertura i altres variables proposades per altres autors (Grau, 2009) ofereixen diferents tipus de projectes que impliquen utilitats diferents en l'aprenentatge. Els centres educatius que estan implantant l'ABP a nivell de centre acostumen a usar en paral•lel diferents modalitats de projectes en relació al paper del context, la interdisciplinarietat i l'estructura de la seqüència didàctica. Una classificació de tipus de projectes que es centrés en aquests aspectes seria d'utilitat com a via per a configurar una dieta didàctica variada. Aquesta via (proposta d'estàndards) va ser la utilitzada per al desenvolupament del model de les WebQuests (Fierro, 2005) (definició de WebQuests i Caceres del Tresor) amb gran èxit en la seva implantació

La necessitat de marcs logístics i d'equipaments de la metodologia ABP no són necessàriament molt diferents d'altres metodologies, però sí que comporten especificitats vinculades als tipus de projectes. En projectes interdisciplinaris, la necessitat de col•laboració entre docents sol implicar hores de reunions i coordinació suplementàries i el protagonisme del context sol implicar complexitats horàries difícils de resoldre. En tot cas, la creació de materials i suports (molts cops, per coherència metodològica, sobre la marxa) imprimeix en l'aplicació de la metodologia un ritme de treball del docent molt exigent. Junt amb això, els equipaments actuals (ordinadors, utillatges específics de laboratori i tallers) són en general lluny de les altes expectatives que s'estan posant des de la societat $i$ les institucions en la metodologia.

La formació del professorat en ABP, partint del que ja fa, però proporcionant alhora orientacions i guies que permetin el desenvolupament de l'ABP com a desplegament del currículum és necessària i urgent, per diferents raons: 1) Hi ha entre el professorat una onada d'interès metodològic que s'ha manifestat en l'ABP a la que cal respondre, no només per a desenvolupar la metodologia, sinó com a evidència de que el professorat és el motor de la renovació pedagògica; 2) Com hem dit a la introducció, determinades visions de l'ABP poden oferir-ne versions distorsionades que en limitin la utilitat i, per dir-ho d'alguna manera "cremin" un cartutx metodològic que -amb les seves limitacionsconstitueix una via potent per a la millora de l'ensenyament de les àrees científiques. Les jornades \#stemabp han volgut ser una aportació a la tasca formativa que ja es fa en aquest àmbit des d'altres espais formatius, com la Xarxa de Competències Bàsiques [5].

En resum, valorem molt positivament aquestes Jornades i el format de cicle de coneixement formació-ponències-publicacions de didàctica que ha resultat en les publicacions citades al tercer apartat d'aquest article. Aquest format ja s'ha desenvolupat en jornades anteriors en relació a les Controvèrsies Sòcio-Científiques (Domènech-Casal i Lope, 2015) i creiem que és una via d'interès en la construcció de coneixement pedagògic. Proposar bastides per acompanyar la identificació dels objectius del projecte, estructurar-ne la seqüència, i avaluar-lo és 
possible i necessari (Ertmer i Simons, 2005). També com a resultat de les jornades, a la web s'ofereixen les bastides usades per a l'activitat de construcció de projectes per part dels participants [6], les produccions dels participants (pòsters) [7] i els Tweets sota el hashtag \#stemabp. Pensem que moltes de les conclusions que es presenten en aquest article són també vàlides per a l'ABP en altres àmbits diferents dels científics.

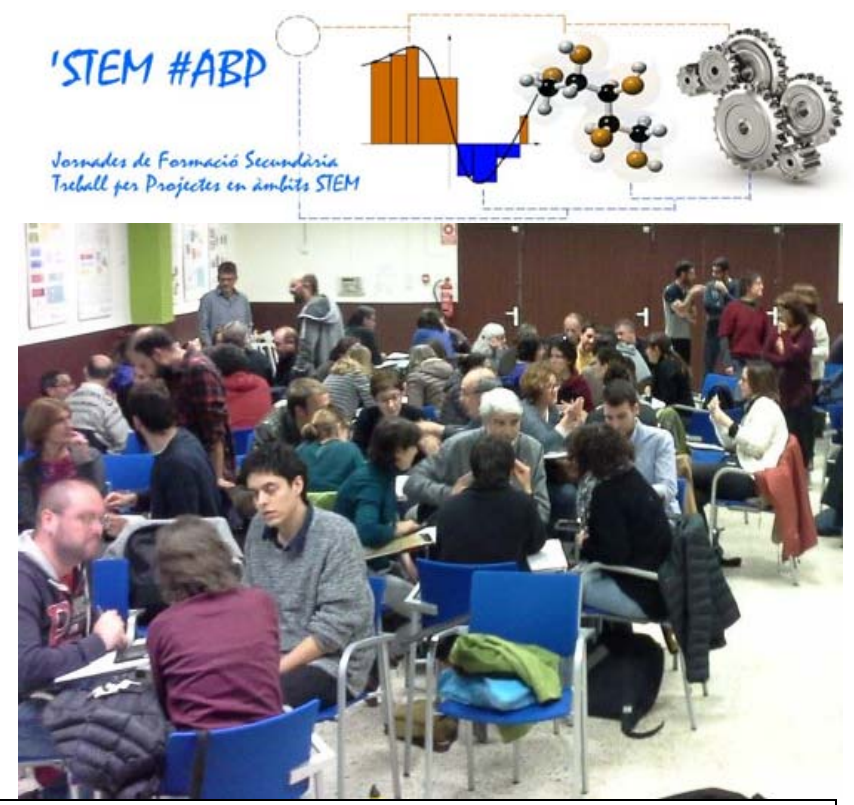

Figura 2. Professors de secundària treballant en equips en el disseny de propostes a les Jornades \#stemabp.

\section{AGRAIIMENTS}

Aquest article emmarca la proposta formativa de les Jornades sobre Aprenentatge Basat en Projectes \#STEMABP [https://stemabp.wordpress.com/] organitzades per el CESIRE del Departament d'Ensenyament i finançades per la Fundació Catalana per la Recerca i la Innovació. Reflexions incloses en aquest article s'emmarquen en la reflexió metodològica duta a terme al grup de recerca consolidat LICEC (referència 2014SGR1492) per AGAUR i finançat per el Ministerio de Economía y Competitividad (referència EDU2015-66643-C2-1-P).

\section{REFERÈNCIES}

BONNEY, R., COOPER, C. B., DICKINSON, J., KELLING, S., PHILLIPS, T., ROSENBERG, K. V., SHIRK, J. (2009). Citizen Science: A Developing Tool for Expanding Science Knowledge and Scientific Literacy. BioScience 59 (11), 977984.

BYBEE, R. W. (2010). What is STEM Education? Science, 329 (5995), 996-996.

CAAMAÑO, A. (2011). Contextualización, indagación y modelización. Tres enfoques para el aprendizaje de la competencia científica en las clases de química. Aula de Innovación Educativa, 207, 17-21.

CHIVA, O., MARTí, M. (2016). Métodos pedagógicos activos y globalitzadores. Conceptualización y propuestas de aplicación. Barcelona, Graó.

DOMĖNECH-CASAL, J. (2016). Apuntes topográficos para el viaje hacia el \#ABP. Cuadernos de Pedagogía, 742, 59-62.

DOMĖNECH-CASAL, J. (en avaluació). Contexto y modelo en el Aprendizaje Basado en Proyectos. Apuntes para el ámbito científico. Alambique, Didáctica de las Ciencias Experimentales (en avaluació).

DOMĖNECH-CASAL, J. (2017). Aprendizaje Basado en Proyectos y Competencia Científica. Experiencias y propuestas para el método de Estudios de Caso. Enseñanza de las Ciencias, en edició.

DOMĖNECH-CASAL, J., LOPE, S. (2015). Les Jornades de Controvèrsia Sòcio-Científica i Recerca i Innovació Responsables: Ciències per a qüestionar i canviar el món. Pensar, comprendre, decidir. Revista Ciències, 30, 29-31.

FIERRO, J.L. (2005). La oportunidad WebQuest. Didáctica, Innovación y Multimedia, 2. [http://www.raco.cat/index.php/DIM/article/view/ 56098].

GILBERT J.K. (2006). On the nature of "context" in chemical education. International Journal of Science Education, 28(9), 957-976.

GRAU, R. (2009). Altres formes de fer ciència. Alternatives a l'aula de secundària. Rosa Sensat, Barcelona.

JORBA, J., CASELLES, E. (1996). La regulació $i$ autoregulació dels aprenentatges. Llibres de l'ICE-UAB. Sèrie Eines i Estratègies. 
JOSA, Z., PINTÓ, E., SERRA, C., FELIU, J. (2017). De l'electricitat a la fusta. Espais d'aprenentatge de la Tecnologia mitjançant projectes. Revista Ciències, 33, 21-28.

KILPATRICK, W.E. (1918). The Project Method: the use of the purposeful act in the educative process. Teachers college, Columbia University.

LARMER, J., MERGENDOLLER, J., BOSS, S. (2015). Setting the Standard for Project Based Learning: A Proven Approach to Rigorous Classroom Instruction. ASCD, Alexandria.

MARCHÁN-CARVAJAL, I., PALOU, L., ROYO, P., DOMĖNECH-CASAL, J. (2017). Els contexts quotidians $i$ els Estudis de Cas com a espai didàctic per a l'ensenyament de les Ciències basat en Projectes. Revista Ciències, 33, 8-14.

MARGELÍ, S. MONSERGAS, M., PERPINYÀ, S., SOL, M., CHIVA, S. (2017). La conjectura i la planificació: Aprenentatge de les matemàtiques mitjançant projectes. Revista Ciències, 33, 3541.

MARTíN, X. (2016). Proyectos con alma. Graó: Barcelona.

MIRÓ, M., SAPERAS, A.M., TARRAGÓ, M., TORDERA, M.R., DOMĖNECH-CASAL, J. (2016). Cinc experiències $i$ reflexions metodològiques sobre l'Aprenentatge Basat en Projectes a les Ciències. Revista Ciències, 32, 23-33.

PLANELLA, M., VILCHES, S., FONT, J., GORRIZ, M., GRAU, R. (2017). Espai, context i creativitat: Aprenentatge de les matemàtiques mitjançant projectes. Revista Ciències, 33, 42-48.

REDONDO, M., RUIZ, N., SÁNCHEZ, S., SOLÉ, R., CALVET, J., CAÑO, M. (2017). Context, Entorn i Servei: l'aprenentatge mitjançant projectes, de les àrees científiques a la Interdisciplinarietat. Revista Ciències, 33, 49-56.

RODRíGUEZ, P. (2015). Adéu a les assignatures: el treball per projectes convenç cada cop més escoles. Diari de l'Educació (20/01/2015)[http://diarieducacio.cat/adeu-a-lesassignatures-el-treball-per-projectes-convenccada-cop-mes-escoles/].

SADLER, T. D. (2009). Situated learning in science education: socio-scientific issues as contexts for practice. Studies in Science Education, 45(1), 142.

SANMARTÍ, N. (2016). Trabajo por proyectos: ¿Filosofía o metodología? Cuadernos de Pedagogía, 472, 44-46.

SANMARTí, N., BURGOA, B., NUÑO, T. (2011) ¿Por qué el alumnado tiene dificultades para utilizar sus conocimientos escolares en situaciones cotidianas? Alambique, Didáctica de las Ciencias Experimentales, 67, 62-68.

TOURON, J.L., VERGARA, E., ARCAS, A., COSTA, M. (2017). Els gèneres de comunicació científica i el laboratori com a espai didàctic per a l'ensenyament de les Ciències basat en Projectes. Revista Ciències, 33, 15-20.

VILLAR, J., ZURITA, S., GIMÉNEZ, F. (2017). Apps $i$ automatismes, oportunitats amb propòsit per a l'aprenentatge de la Tecnologia mitjançant projectes. Revista Ciències, 33, 29-34.

\section{NOTES}

[1] Web de les Jornades STEM-ABP: https://stemabp.wordpress.com/

[2] Formació CTM del Departament d'Ensenyament:

http://xtec.gencat.cat/ca/formacio/formaciogener alprofesso-

rat/actualitzacio_cientifica_didactica/ctm/oic

[3] CoRubrics:

https://sites.google.com/site/corubricscat/

[4] AssessABP: https://projecteindcomp.wordpress.com/2016/06 101/avaluacio-dabp-interdisciplinars-per-criterisdavaluacio-i-ccbb-assessabp/

[5] Xarxa de Competències Bàsiques: http://xtec.gencat.cat/ca/curriculum/xarxacb/treb all-projectes/

[6] Xarxa de Competències Bàsiques: http://xtec.gencat.cat/ca/curriculum/xarxacb/treb all-projectes/

[7] Materials de les Jornades STEMABP: https://stemabp.wordpress.com/2016/11/06/mat erials-de-les-jornades/ 